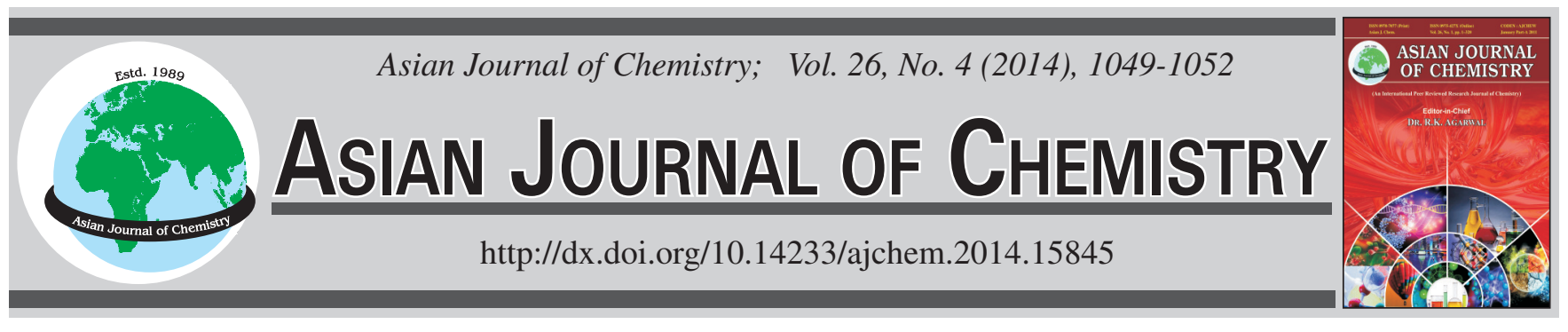

\title{
Detection of Blood Lead Content by Graphite Furnace Method
}

\author{
JiAN YANG*, LiXIA CHI and QUN LiU
}

Institute of Disaster Prevention, Langfang, P.R. China

*Corresponding author: Fax: +86 10 57901407; Tel: +86 10 57901401; Email: yangjianpearl@ 163.com

Received: 30 May 2013;

Accepted: 7 August 2013;

Published online: 15 February 2014;

AJC-14697

\begin{abstract}
A research on the relationship between the life span and the change on absorbance of graphite tubes from different manufacturers, when employed to test the same sample, has been conducted. The results show that only graphite tubes of high quality can achieve the standard that the absorbance fluctuations are less than $10 \%$ when detecting the same sample within their life cycle. In the determination of blood lead by graphite furnace method, the calibration curve of EDTA, taking the place of human blood used in National guide to clinical laboratory procedures, can detect accurately the blood lead content in lyophilized bovine blood.
\end{abstract}

Keywords: Graphite furnace, Blood, Lead, Matrix effect.

\section{INTRODUCTION}

With the extensive use of substances containing lead in modern society, lead has become an important environmental pollutant. The lead poisoning in adults can cause fatigue, depression, heart failure, kidney deficiency, hypertension, abdominal pain, joint pain, reproductive disorders, anemia and other diseases. Lead poisoning on the part of pregnant women can lead to miscarriage, stillbirth, low birth weight, fetal dysplasia, etc. Children lead poisoning can cause the loss of appetite, stomach pain, insomnia, constipation, learning disabilities, nausea, diarrhea, fatigue, low IQ, anemia, etc. With the improvement of human cognition and the increasing popularity of medical devices used to detect the blood lead content in human body by graphite furnace method, detection of blood lead content by using graphite furnace method has become a basic testing item in the hospital laboratories ${ }^{1}$. The effort to simplify the procedure in the detection of blood lead content by graphite furnace method and to ensure the accuracy and repeatability of inspection data has become an eternal theme of the field. This paper attempts to offer some insights into the long-neglected impact exerted by the life span of graphite tubes on the test of absorbance. The results show that only graphite tubes of high quality can achieve the standard that the absorbance fluctuations are less than $10 \%$ when detecting the same sample within their life cycle. In addition, this study uses EDTA to replace the national guide to clinical laboratory procedures, in which human blood is employed to make the calibration solution $^{2}$, thus simplifying the procedures for the preparation of calibration solutions. At the same time, due to the lack of biological components in calibration solution, there is no need to keep the calibration solution under cryopreservation.

\section{EXPERIMENTAL}

AA7000 Series Atomic Absorption Spectrophotometer and Automatic Sampler manufactured by East \& West Analytical Instruments, Inc. Certified reference material of lead and cadmium in lyophilized bovine blood: GBW09139GBW09140, Institute for Occupation Health and Poisoning Control, Chinese Center for Disease Control and Prevention; Standard Solution Pb: GBW08619, China Institute of Metrology; High purity deionized water (resistivity of $18.2 \mathrm{M} \Omega / \mathrm{cm}$ ); Nitric acid: BV-grade III; Ethylenediaminetetraacetic acid: AR Grade; $\mathrm{NH}_{4} \mathrm{H}_{2} \mathrm{PO}_{4}$ : AR Grade; Triton X-100: AR Grade.

Working condition of instruments: A spectral line of $283.31 \mathrm{~nm}$ and a spectral band of $0.2 \mathrm{~nm}$ were selected. Current of Element Lamp operated at $1.5 \mathrm{~mA}$ and Current of D lamp operated at $80 \mathrm{~mA}$ was used. The deuterium lamp background correction system was used. Sample size: $10 \mu \mathrm{L}$.

Graphite furnace temperature program: The program can be shown in the following (Table-1)

Blood sample treatment: Matrix components of blood are very complicated, thus in most cases, matrix modifier should be added to eliminate matrix interference. In this study, the researchers adopt the commonly used Triton X-100 and the $\mathrm{NH}_{4} \mathrm{H}_{2} \mathrm{PO}_{4}$ system as the matrix modifier ${ }^{3}$. The results show that Triton X-100 at a concentration of 0.1-1\% and $\mathrm{NH}_{4} \mathrm{H}_{2} \mathrm{PO}_{4}$ at a concentration of in $0.5-2 \mathrm{~g} / \mathrm{L}$ would not exert any negative effect on the final results. Therefore, Triton X-100 at a concentration of $0.2 \%$ and $\mathrm{NH}_{4} \mathrm{H}_{2} \mathrm{PO}_{4}$ at a concentration of $0.5 \mathrm{~g} / \mathrm{L}$ 
TABLE-1

TEMPERATURE PARAMETER OF GRAPHITE FURNACE

\begin{tabular}{lcccc}
\hline \multicolumn{1}{c}{ Step } & $\begin{array}{c}\text { Start temp. } \\
\left({ }^{\circ} \mathrm{C}\right)\end{array}$ & $\begin{array}{c}\text { Start temp. } \\
\left({ }^{\circ} \mathrm{C}\right)\end{array}$ & Durat (s) & Inner gas \\
\hline Dry-up & $60-$ & 90 & 25 & on \\
Dry-up & $90-$ & 120 & 10 & on \\
Ashing & $120-$ & 250 & 15 & on \\
Ashing & $250-$ & 500 & 8 & on \\
Ashing & 500 & 500 & 5 & on \\
Ashing & 500 & 500 & 3 & off \\
Atomiz & 2000 & 2000 & 4 & off \\
Clean & 2200 & 2200 & 3 & on \\
Cooling & 0 & 0 & 25 & on \\
\hline
\end{tabular}

were added to the calibration solution and sample solution. When adding nitric acid to the hemolytic system, some dark brown precipitates appear in the blood samples, which affect the uniformity of samples. Consequently, neutral hemolytic system was chosen in this study. The blood samples were diluted by 10 times with a reference to national clinical laboratory procedures

\section{RESULTS AND DISCUSSION}

Impact of graphite tube life span on data repeatability: Owing to the fact that there is a large number of lead blood samples in clinical practice and that the instruments will work continuously for a long time, the pyrolytic coated platform graphite tubes will be the best choice for the present study. Three graphite tubes of the same specifications from different manufactures were marked as graphite tube A, graphite tube $\mathrm{B}$ and graphite tube $\mathrm{C}$. They were employed continuously to test the same sample so as to examine the data fluctuations in different stage of life of these graphite tubes. Because new graphite tubes should be exposed to burning when used for the first time, the investigation began at the second time of their usage. The experiments would end when the deviation of continuous test data was greater than $10 \%$ or the graphite tubes were damaged. The experimental data are shown in Table-2, which proves that the graphite tubes in domestic markets are of uneven quality and only those graphite tubes of good quality can meet the requirements that the data volatility should be within $10 \%$ and have a longer service life at the same time.

\section{Preparation of calibration solution}

Choice of matrix modifier: According to "the preparation method of the clinical laboratory operating procedures" and "WS/T20-1996 graphite furnace atomic absorption spectrometric method in blood lead", the preparation of calibration curve is as follows: add the normal human blood to the calibration solution to get the sample matrix interchangeability as the samples ${ }^{4}$. However, when the human blood added to the calibration solution is of a high lead content, the accuracy for the low lead samples will be influenced. Therefore, this research selected different matrix modifiers, namely ascorbic acid, tartaric acid, oxalic acid and EDTA respectively in the experiments. The researchers found that EDTA has an obvious edge as a matrix modification, which may be attributed to the fact that lead, when combined with EDTA, can form some chelate pentacyclic structures so as to improve the stability of lead elements in the dry and ashing stage and to reduce the evaporation of lead before the atomization stage. Then the relationship between the concentrations of EDTA and matrix effects was tested. Figs. 1 and 2 show respectively the relationship between absorbency and EDTA concentration when concentration of lead is $10 \mu \mathrm{g} / \mathrm{L}$ and $20 \mu \mathrm{g} / \mathrm{L}$. absorbance (absorbency) and the change of EDTA concentration. With the increase of lead concentration in solution, the inflection point to the shift of low EDTA concentration in human blood samples, $\mathrm{Pb}$ in diluted 10 times, generally less than $20 \mu \mathrm{g} / \mathrm{L}$, therefore, the concentration of selected EDTA as $0.03 \mathrm{~g} / \mathrm{L}$.

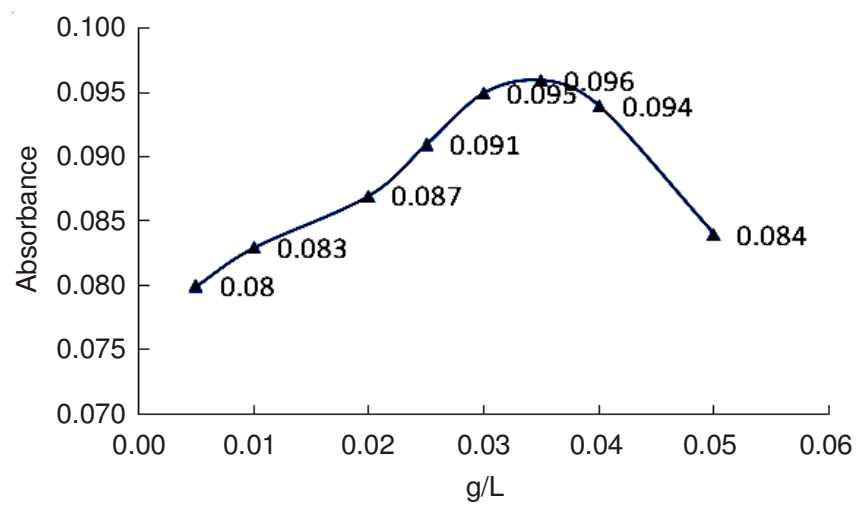

Fig. 1. Relationship between absorbency and EDTA concentration when concentration of lead is $10 \mu \mathrm{g} / \mathrm{L}$

TABLE-2

RESULTS FOR THE LIFE SPAN TESTS ON GRAPHITE TUBES

\begin{tabular}{lcccc}
\hline & Frequency of use of graphite tubes & Graphite tube A & Graphite tube B & Graphite tube C \\
\hline & 2 & 0.0552 & 0.0673 & 0.0553 \\
& 11 & 0.0561 & 0.0632 & 0.0562 \\
& 151 & 0.0577 & 0.0600 & 0.0520 \\
& 201 & 0.0534 & 0.0587 & 0.0488 \\
& 251 & 0.0531 & 0.0580 & 0.485 \\
Absorbance changes when used & 301 & 0.0543 & 0.0504 & 0.440 \\
to test the same samples & 351 & 0.0521 & 0.0462 & 0.360 \\
& 401 & 0.0533 & 0.0440 & - \\
& 451 & 0.0524 & 0.0399 & - \\
& 501 & 0.0525 & 0.0380 & - \\
"-" indicates the end of the experiments & 551 & 0.0500 & - & - \\
\hline
\end{tabular}

\footnotetext{
"-" indicates the end of the experiments
} 


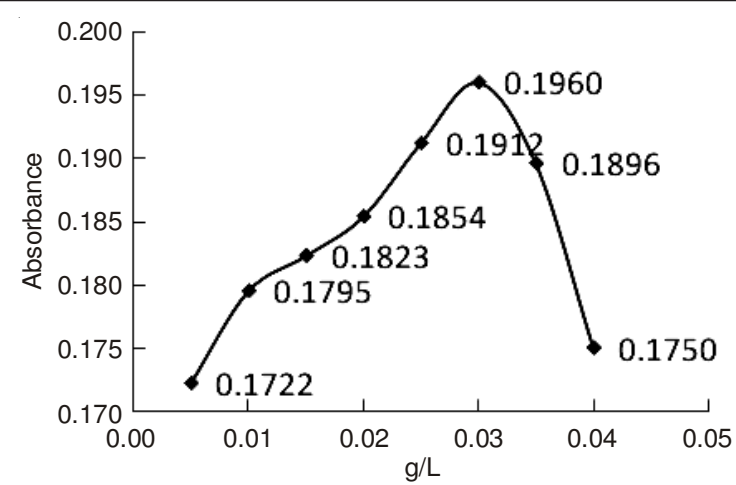

Fig. 2. Relationship between absorbency and EDTA concentration when concentration of lead is $20 \mu \mathrm{g} / \mathrm{L}$

Makeup of calibration solution: In order to investigate the effect of EDTA calibration solution, three different calibration solutions (marked as calibration solution A, calibration solution B and calibration solution C) are made in the following ways: both blood and EDTA are excluded; blood added; EDTA added.

Makeup of calibration solution A: Freshly made 1000 $\mu \mathrm{g} / \mathrm{LPb}$ calibration solution measured $0 \mathrm{~mL}, 0.25 \mathrm{~mL}, 0.5 \mathrm{~mL}$, $1 \mathrm{~mL}, 1.5 \mathrm{~mL}, 2 \mathrm{~mL}$ was put into $50 \mathrm{~mL}$ volumetric flask respectively, then the calculation amount of $\mathrm{NH}_{4} \mathrm{H}_{2} \mathrm{PO}_{4}$ and Triton $\mathrm{X}-100$ were added in turn. The concentration of Triton X-100 was $0.2 \%$ and that of $\mathrm{NH}_{4} \mathrm{H}_{2} \mathrm{PO}_{4}$ was $0.5 \mathrm{~g} / \mathrm{L}$ and the concentration of nitric acid solution $0.2 \%$. In order to maintain the stability of the solution for a long term, the volume was determined to be $50 \mathrm{~mL}$. The concentrations of standard series were $5 \mu \mathrm{g} / \mathrm{L}, 10 \mu \mathrm{g} / \mathrm{L}, 20 \mu \mathrm{g} / \mathrm{L}, 30 \mu \mathrm{g} / \mathrm{L}, 40 \mu \mathrm{g} / \mathrm{L}$ respectively.

Makeup of calibration solution B: the calibration solution was made up with a reference to the calibration curve drawing method in "the preparation method of the clinical laboratory operating procedures", as is shown in Table-3 "National Clinical Laboratory Operation Rules" in the calibration solution according to Table-3. The calibration curve was drawn with the absorbance value of 1-5 tubes minus $t$ absorbance value of tube No. 0 as the ordinate and the standard lead content as the abscissa.

\begin{tabular}{lcccccc}
\multicolumn{7}{c}{ TABLE-3 } \\
\multicolumn{7}{l}{ THE MAKEUP OF CALIBRATION SOLUTION B } \\
\hline Tube & 0 & 1 & 2 & 3 & 4 & 5 \\
\hline Triton X-100 (\%) & 0.1 & 0.1 & 0.1 & 0.1 & 0.1 & 0.1 \\
$\begin{array}{l}\text { Normal human } \\
\text { blood (mL) }\end{array}$ & 0.04 & 0.04 & 0.04 & 0.04 & 0.04 & 0.04 \\
Lead content (ug/L) & 0 & 5 & 10 & 20 & 30 & 40 \\
\hline
\end{tabular}

Makeup of calibration solution C: Freshly made $1 \mathrm{mg} / \mathrm{L}$ $\mathrm{Pb}$ calibration solution measured $0 \mathrm{~mL}, 0.25 \mathrm{~mL}, 0.5 \mathrm{~mL}, 1 \mathrm{~mL}$, $1.5 \mathrm{~mL}, 2 \mathrm{~mL}$ was put into $50 \mathrm{~mL}$ volumetric flask respectively, then the calculation amount of $\mathrm{NH}_{4} \mathrm{H}_{2} \mathrm{PO}_{4}$ and Triton X-100 and EDTA were added in turn. The concentration of Triton X100 was $0.2 \%$, that of $\mathrm{NH}_{4} \mathrm{H}_{2} \mathrm{PO}_{4}$ and EDTA were $0.5 \mathrm{~g} / \mathrm{L}$ and $0.03 \mathrm{~g} / \mathrm{L}$ respectively and the concentration of $\mathrm{HNO}_{3} 0.2 \%$. In order to maintain the stability of the solution for a long term, the volume was determined to be $50 \mathrm{~mL}$. The concentrations of standard series were $5 \mu \mathrm{g} / \mathrm{L}, 10 \mu \mathrm{g} / \mathrm{L}, 20 \mu \mathrm{g} / \mathrm{L}, 30 \mu \mathrm{g} / \mathrm{L}, 40$ $\mu \mathrm{g} / \mathrm{L}$ respectively.

Under the determined experimental condition, the absorbance values of Calibration solution $\mathrm{A}, \mathrm{B}$ and $\mathrm{C}$ were measured respectively and then the calibration curves were drawn (As is shown in Fig. 3). When the matrix modifier is not added to the solution, lead absorbance is very low, which shows lead has suffered serious losses in the drying and ashing process and the matrix improvement effects of EDTA and the blood samples were basically the same. Regression equation of Calibration solution B (regression equation) is $\mathrm{y}=0.0056+$ $0.0046 \mathrm{x}$; and that of calibration solution $\mathrm{C} ; \mathrm{y}=0.0027+0.0049 \mathrm{x}$.

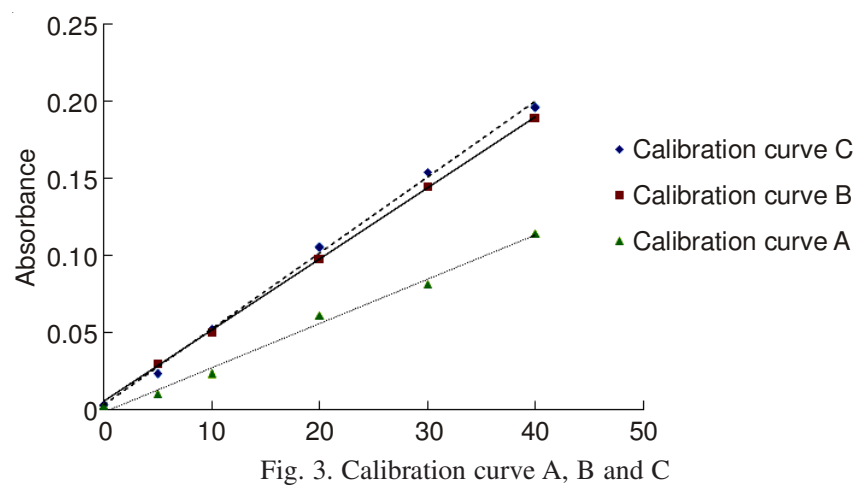

Precision experiment on calibration solution: When the instrument was kept in a stable condition, the precision of calibration solution $\mathrm{C}$ was test repeatedly (11 times). The results are shown in Table-4, which shows that the stability of the solution with EDTA added as the matrix modifier is very good.

\begin{tabular}{ccccc}
\multicolumn{5}{c}{ TABLE-4 } \\
PRECISION OF CALIBRATION SOLUTION C \\
\hline $\begin{array}{c}\text { Concentration of calibration } \\
\text { solution }(\mu \mathrm{g} / \mathrm{L})\end{array}$ & $\mathrm{n}$ & Mean & S.D. & $\mathrm{CV}(\%)$ \\
\hline 5 & 11 & 0.0230 & 0.0010 & 4.2 \\
10 & 11 & 0.0527 & 0.0011 & 2.1 \\
20 & 11 & 0.1052 & 0.0019 & 1.8 \\
30 & 11 & 0.1543 & 0.0023 & 1.5 \\
40 & 11 & 0.1960 & 0.0022 & 1.1 \\
\hline
\end{tabular}

Tests of standard substance: In order to examine the accuracy of the test method, the above mentioned calibration curve and sample treatment method were adopted to determine the certified reference material of lead and cadmium in lyophilized bovine blood (GBW09139-GBW09140), as is shown in Table-5. The results show that the method is reliable and accurate.

TABLE-5

TEST OF CERTIFIED REFERENCE MATERIAL OF LEAD AND CADMIUM IN LYOPHILIZED BOVINE BLOOD $(\mu \mathrm{g} / \mathrm{L})$

\begin{tabular}{lccccccc}
\hline Sample code & Standard value and uncertainty & Value 1 & Value 2 & Value 3 & Mean & sd & CV \\
\hline GBW09139 & $122 \pm 15$ & 130 & 125 & 132 & 129 & 3.6 & $2.8 \%$ \\
GBW09140 & $311 \pm 12$ & 306 & 311 & 308 & 308 & 2.5 & $0.8 \%$ \\
\hline
\end{tabular}




\section{Conclusion}

There is a close correlation between the quality of graphite tubes and the reproducibility of inspection data in clinical blood lead content test by graphite furnace method. As a result, it is of great importance to select graphite tubes of high quality, thus improving the quality of clinical laboratory data. In addition, EDTA can be used to replace biological samples (human blood) to make up calibration solution when using graphite furnace method to test blood lead content, which can reduce the difficulty of the preservation of calibration solution so as to improve the reproducibility of clinical data.

\section{ACKNOWLEDGEMENTS}

This study was supported by A Project of Hebei Province Higher Educational Science and Technology Program (No. Z2012052).

\section{REFERENCES}

1. H. Hu, D. Hashimoto and M. Besser, Arch. Environ. Health, 51, 52 (1996).

2. National Guide to Clinical Laboratory Procedures, edn 3, p. 397 (2009).

3. Z. Yuan, L. Wenhong and L. Hui, Chin. J. Prev. Med, 34, 4 (2000).

4. WS/T20-1996 Blood-Determination of Lead-Graphite Furnace Atomic Absorption Spectrometric Method.

\title{
ERRATUM
}

\section{Spectroscopic Studies on the Interaction of Polydatin with Bovine Serum Albumin}

\author{
XIAOLI LiU ${ }^{1,2}$ and Hua $\mathrm{Li}^{3, *}$
}

${ }^{1}$ College of Life Sciences, Northwest University, Xi'an, P.R. China

${ }^{2}$ College of Environmental Science and Engineering, Chang'an University, Xi'an, P.R. China

${ }^{3}$ Institute of Analytical Science, Northwest University, Xi'an, P.R. China

*Corresponding author: Tel: +86 29 88302635; E-mail: nwufxkx2012@126.com

The following corrections are incorporated as follows:

\begin{tabular}{|c|c|}
\hline Incorrect & Correct \\
\hline $\begin{array}{l}292 \\
-\quad 297 \\
-\quad 302\end{array}$ & $\begin{array}{l}\text { - } 292 \\
\text { - } 297 \\
\text { - } 302\end{array}$ \\
\hline $\begin{array}{l}\text { Fig. } 4 \text { UV-vis absorption spectra of BSA (1), } \\
\text { polydatin (2) and the difference spectrum } \\
\text { between TRES-BSA }(1: 1) \text { and polydatin (3). }\end{array}$ & $\begin{array}{l}\text { Fig. } 4 \text { UV-vis absorption spectra of BSA (1), } \\
\text { polydatin (3) and the difference spectrum } \\
\text { between TRES-BSA }(1: 1) \text { and polydatin (2). }\end{array}$ \\
\hline In Fig. 7(a): & -s-helix $53 \%$ \\
\hline
\end{tabular}

